\title{
CARACTERIZAÇÃO FÍSICO-QUÍMICA DE OKARA E APLICAÇÃO EM PÃES DO TIPO FRANCÊS ${ }^{1}$
}

\author{
Simone BOWLES ${ }^{2, *}$, Ivo Motin DEMIATE ${ }^{3}$
}

\begin{abstract}
RESUMO
A composição química do extrato aquoso de soja e de seu subproduto okara foi determinada. Em base seca, para o okara, o teor dos componentes encontrados foi de $2,8 \%$ de cinzas, $37 \%$ de proteínas, $13 \%$ de lipídios, $42,5 \%$ de fibras alimentares e $4,7 \%$ de carboidratos solúveis. Para o extrato aquoso esses valores foram de 2,4\% de cinzas, 33\% de proteínas, 17,7\% de lipídios, 41,4\% de carboidratos solúveis e traços de fibras alimentares. Pães do tipo francês foram adicionados de $0,5,10$ e $15 \%$ de okara seco. Foi realizada a análise sensorial por meio do teste de preferência que demonstrou que os pães contendo $5 \%$ e $10 \%$ de okara tiveram níveis de aceitação iguais e superiores àqueles contendo $15 \%$. Assim, os pães contendo $10 \%$ de okara foram submetidos ao teste sensorial de intenção de compra, revelando média 4,2 numa escala de 1 a 5, ou seja, uma avaliação favorável do ponto de vista comercial. Pães adicionados de $5 \%$ e $10 \%$ de okara podem ser denominados produtos "fonte" e "ricos" em fibras, respectivamente.

Palavras-chave: okara, soja, subproduto.
\end{abstract}

\section{SUMMARY}

PHYSICOCHEMICAL CHARACTERIZATION OF THE SOYMILK BYPRODUCT - OKARA. The chemical composition of soymilk and its byproduct okara were determined. In dry matter, for okara the concentration of nutrients was: $2.8 \%$ of ash, $37 \%$ of proteins, $13 \%$ of lipids, $42.5 \%$ of dietary fiber and $4.7 \%$ of soluble carbohydrates. For soymilk these values were: $2.4 \%$ of ash, $33 \%$ of proteins, $17.7 \%$ of lipids, $41.4 \%$ of soluble carbohydrates and traces of fibers. Dried okara was added to French type bread at $0,5,10$ and $15 \%$. A sensorial analysis was developed using a preference test which showed that bread containing 5 and $10 \%$ of okara had levels of acceptance that were equal and higher than bread containing $15 \%$. Bread produced with $10 \%$ okara was tested in a purchase intent test. The result was on average 4.2 in the range of 1 to 5 , which shows a positive evaluation of this product. Bread containing 5 and $10 \%$ of added okara can be labeled as "source" and "rich" in fiber, respectively.

Keywords: okara, byproduct, soy.

\section{1 - INTRODUÇÃO}

A soja (Glycine max), uma leguminosa conhecida pelos chineses há cerca de cinco mil anos, passou a ser cultivada nos Estados Unidos apenas no século XX [27], tendo se tornado um produto agrícola e grande importância naquele e em outros países.

A soja chegou ao Brasil em 1908, a ampliação de seu cultivo ocorreu nos anos 70 com o aumento do interesse na produção e demanda internacional de óleo. Os Estados Unidos são os maiores produtores de soja, seguidos pelo Brasil, Argentina e China, responsáveis por aproximadamente $90 \%$ da produção mundial [28]. A produção anual mundial de soja, em 2004, foi superior a 206 milhões de toneladas [14].

A comercialização da soja é internacionalizada e a safra brasileira de soja cresceu mais de $97 \%$ nos últimos 10 anos [14], sendo os Estados de Mato Grosso, Paraná e Rio Grande do Sul responsáveis por $65 \%$ da produção nacional [28].

\footnotetext{
${ }^{1}$ Recebido para publicação em 24/10/2000. Aceito para publicação em 6/7/2006 (001625)

${ }^{2}(U T F P R-P G), A v$. Monteiro Lobato, Km 4, CEP 84016-210,

Ponta Grossa (PR),

E-mail: simonebowles@gmail.com

${ }^{3}$ Departamento de Engenharia de Alimentos,

Universidade Estadual de Ponta Grossa, Campus Uvaranas,

Av. Carlos Cavalcanti, 4748, CEP 84030-900, Ponta Grossa (PR)

* A quem a correspondência deve ser enviada
}

Parte do impacto que a cultura de soja gera se deve aos investimentos realizados nos últimos 25 anos por instituições como a Empresa Brasileira de Pesquisa Agropecuária [2], responsável pela adaptação desta leguminosa em muitas regiões do País [8]. Sua importância econômica e nutricional é devida ao elevado teor de lipídios e proteínas [20], responsáveis por cerca de $60 \%$ do peso seco da soja, sendo o restante composto por carboidratos (aproximadamente 35\%) e cinzas (cerca de 5\%). A umidade representa em média 13\% dos grãos, que em base úmida contêm aproximadamente $35 \%$ de proteínas, $17 \%$ de lipídios, $31 \%$ de carboidratos e $4,4 \%$ de cinzas [20]. Cerca de $8 \%$ do grão da soja corresponde à película externa, $90 \%$ aos cotilédones e $2 \%$ ao eixo do hipocótilo. O cotilédone contém a maior proporção de proteínas e lipídios da soja, enquanto que a película externa contém os menores teores destes componentes.

A soja apresenta componentes de comprovada ação benéfica à saúde humana. Destacam-se as isoflavonas [20]; [1], as proteínas [7, 21, 23, 28] os fosfolipídios [2, 29], os antioxidantes [9], as vitaminas [9, 13] e as fibras [8]. Assim, o consumo de produtos à base de soja na dieta contribui para uma melhor qualidade de vida, havendo relatos da redução da concentração sérica de colesterol e triglicerídeos, prevenindo doenças crônico-degenerativas e alguns tipos de câncer [22]. Nos Estados Unidos, em 1999, o Food and Drug Administration (FDA) divulgou um documento para conhecimento público, ressaltando as ações em potencial da soja na prevenção de doenças cardíacas e autorizando 
as indústrias, daquele país, a informar nos rótulos de seus produtos as propriedades benéficas associadas ao consumo de soja. Anteriormente, esse mesmo órgão anunciou que a ingestão diária de 25 g de proteína de soja, como parte de uma dieta com baixa concentração de ácidos graxos saturados e colesterol, poderia reduzir o risco de doenças cardíacas. Alimentos à base de soja e conseqüentemente de suas proteínas reduzem o colesterol LDL, elevando os níveis do HDL colesterol [29].

Vários Institutos de Pesquisa e Universidades têm procurado desenvolver produtos à base de soja, ou enriquecidos com tal leguminosa, de maneira que estes possam substituir, com vantagens, alimentos de origem animal.

Produtos como o tofu, o "leite" de soja, o iogurte à base de soja, a "carne" de soja, o missô, o isolado protéico e a farinha de soja são alimentos que fazem parte da dieta japonesa e de outros países orientais. Estes produtos são fontes de isoflavonas, antioxidantes e outros componentes que trazem benefícios à saúde. O conteúdo de fibras da soja, além de auxiliar na redução de colesterol e triglicerídeos, possui atividade mecânica na formação do bolo fecal, propriedade esta relacionada a sua porção insolúvel [28].

A soja processada de maneiras diversas dá origem a produtos e subprodutos de grande importância, como os já mencionados. O extrato aquoso de soja ("leite" de soja) gera em seu processamento um subproduto denominado okara.

O extrato aquoso de soja é um produto obtido a partir da lavagem, maceração e aquecimento de grãos de soja. Os grãos lavados e macerados são moídos e aquecidos para, então, passarem por um processo de filtração que separa o extrato aquoso de seu subproduto, o okara [23]. Acreditase que o extrato aquoso de soja tenha sido elaborado pela primeira vez na China durante o segundo século depois de Cristo [19]. Desde então, este extrato aquoso tem sido consumido na China diariamente.

A composição química média do extrato aquoso de soja, comparada aos leites de vaca e humano, está demonstrada na Tabela 3. De maneira geral, possui aproximadamente de $8 \%$ a $10 \%$ de sólidos totais, dependendo da extração e do equipamento utilizado. Destes sólidos, 3,6\% correspondem às proteínas, 2,0\%, à fração lipídica, 2,9\%, a carboidratos e $0,5 \%$, a cinzas.

Cerca de 1,1 kg de okara fresco (base úmida) é produzido pelo processamento de $1 \mathrm{~kg}$ de grãos de soja mais quantidade padrão de água, para obtenção do extrato aquoso [23]. Da desidratação de 1 kg deste subproduto, são obtidos aproximadamente $250 \mathrm{~g}$ de okara seco (farinha).

No que diz respeito à composição do subproduto okara, pesquisas demonstram sua elevada qualidade nutricional e possíveis aplicações, visando melhorias em produtos alimentícios. Em sua pesquisa, WANG \& CAVINS [32]. encontraram cerca de $20 \%$ de proteínas e $11 \%$ de lipídios em okara [23].
VAN DER REIT, CILLIERS \& DATEL [30]. relataram a composição centesimal média encontrada em okara de três cultivares de soja dos EUA (Edgar, Hutton e Prima).

Todavia, apesar dos componentes nutritivos e funcionais do subproduto do extrato aquoso de soja, okara, do potencial para aplicação em produtos alimentícios, seu uso é mais comum na fabricação de rações para animais [24].

A história do pão está diretamente relacionada à história da humanidade de maneira geral. Existem dados que registram a utilização do pão e produtos à base de trigo há 3000 - 4000 anos a. C. em povos da Mesopotâmia e Egito. A evolução da tecnologia de panificação se deve principalmente ao grande consumo deste produto.

O pão é um alimento de grande importância do ponto de vista nutricional, por seu conteúdo protéico e por ser fonte de energia, pelo seu elevado teor em carboidratos [26]. É um dos produtos alimentícios mais estudados com relação a características como a elasticidade da massa, o aspecto da crosta, a crocância da casca, o volume e o sabor dos pães em diferentes situações de produção, como o tratamento da massa, a qualidade do trigo, entre outras [3, 27].

Devido ao seu amplo consumo, o pão branco revela-se um produto que pode ser enriquecido com subprodutos para fornecimento de nutrientes ou componentes especiais. Concentrações significativas de fibras podem ser adicionadas ao pão, para que seja um alimento considerado como fonte de fibras e apresente propriedades benéficas à saúde do consumidor. A quantidade e a qualidade das fibras adicionadas podem alterar o produto final quanto a suas características reológicas e sensoriais [33].

A utilização de soja no enriquecimento de vários produtos alimentícios tem sido citada com freqüência, estando tais produtos disponíveis para comercialização.

Na Universidade Nacional de La Plata - Argentina, em 2002, foi proposto um projeto piloto de empreendimento solidário de produção, elaboração e distribuição de alimentos de soja para assistência alimentar em refeitórios comunitários daquela cidade. O projeto foi denominado "Ajudando a crescer com Soja”, e fazem parte deste projeto a Universidade Nacional de La Plata, colégios profissionalizantes da província de Buenos Aires, distrito de La Plata, entre outros. Neste projeto, vários produtos provenientes de soja entram como matérias-primas básicas no processamento de alimentos. O subproduto okara faz parte das matérias-primas utilizadas, sendo relatado como um composto de alto valor nutritivo. O okara é incorporado em alimentos como hamburgers e produtos de panificação [25].

A suplementação de produtos alimentícios com okara foi relatada em 2002, por WALISZEWSKI, PARDIO \& CARREON [31]. Os autores realizaram uma avaliação química e sensorial de okara, incluindo um perfil da composição em aminoácidos, e foram incorporadas porcentagens de 5, 10 , 15, 20 e $25 \%$ deste subproduto em Tortillas. Os autores demonstraram que concentrações de até $10 \%$ de okara podem ser adicionadas às Tortillas, alcançando níveis satisfatórios 
de aceitação. Além de alcançar efeitos satisfatórios quanto à sua aceitação, o enriquecimento das Tortillas resultou num importante aumento na concentração de aminoácidos como lisina, triptofano, treonina e isoleucina [32].

GENTA et al. [15] publicaram, em 2002, artigo sobre a produção e aceitação de um doce de soja, elaborado a partir do subproduto okara. Na formulação $\mathbf{A}$ foram usados $18,3 \%$ de okara e $27,4 \%$ de amendoim: na $\mathbf{B}, 27,4 \%$ e $18,3 \%$, respectivamente; e na formulação C, $36,6 \%$ e 9, $1 \%$. Foram determinadas a aceitação e a preferência entre as amostras. As conclusões a que os autores chegaram foram que amostras contendo concentrações menores de okara apresentaram maior grau de aceitação [15].

Assim, o presente trabalho tem por objetivos determinar a composição centesimal do okara e estabelecer uma concentração do subproduto para ser adicionada em pães do tipo francês, que tenham um resultado satisfatório no que diz respeito a sua aceitação e possível compra.

\section{2 - MATERIAL E MÉTODOS}

\section{1 - Material}

O subproduto okara, da obtenção do extrato solúvel de soja e cedido pela Secretaria Municipal de Abastecimento da Prefeitura Municipal de Curitiba-PR, foi congelado para armazenamento. Para utilização, foi desidratado e triturado.

Os ingredientes necessários para o desenvolvimento do produto alimentício a ser elaborado foram adquiridos no comércio local. Os equipamentos de panificação utilizados para a produção dos pães foram: masseira MR compacta marca Perfecta Curitiba, boleador Hypo 0,5 HP e forno a vapor Digo Mec - Perfecta Curitiba com estufa acoplada.

Para as análises físico-químicas, os equipamentos empregados foram: mufla Tecnal, estufa com circulação de ar Tecnal, estufa a vácuo Tecnal, espectrofotômetro FEMTO 432.

Os reagentes utilizados de padrão analítico foram: ácido sulfúrico concentrado, hidróxido de sódio 40\%, hexano, pepsina NF, pancreatina $4 \times \mathrm{NF}$, alcalase, alfa-amilase termo-estável, amiloglicosidase, tampão fosfato ( $\mathrm{pH} 6,0$ ), ácido clorídrico 4M, hidróxido de sódio $4 \mathrm{M}$, etanol 95\%, acetona, sulfato de potássio anidro, sulfato de cobre anidro, ácido bórico $2 \%$, ácido clorídrico 0,02 N, vermelho de metila. As vidrarias utilizadas foram: pipetas graduadas e volumétricas, béquer, erlenmeyer, balões de destilação, mantas de aquecimento, condensadores, balóes volumétricos, tubos para digestão, cadinhos de porcelana.

\section{2 - Métodos}

\subsection{1 - Avaliação da composição química do okara}

O teor de lipídios das amostras foi determinado gravimetricamente após extração por meio de processo de destilação por Soxhlet e solvente hexano; o teor de umidade foi obtido pelo método de secagem em estufa a $105^{\circ} \mathrm{C}$ por $6 \mathrm{~h}$; as cinzas foram determinadas por meio de incineração dupla (com carbonização prévia) a $550{ }^{\circ} \mathrm{C}$; para a determinação das proteínas foi usado o método de Kjeldahl, e fator de conversão de nitrogênio em proteínas de 6,25 [17]; e para a determinação das fibras alimentares foi usado o método enzimático-gravimétrico [1]. O teor de isoflavonas foi determinado por Cromatografia Líquida de Alta Eficiência (CLAE) [5].

\subsection{2 - Elaboração dos pães}

Foram utilizadas concentrações de 0, 5, 10 e 15\% do subproduto okara em adição à farinha de trigo na formulação base do produto panificado, estabelecidas de acordo com testes prévios e dados de literatura [26, 33]. A formulação padrão utilizada para a elaboração dos pães é mostrada na Tabela 1 .

A formulação padrão, bem como aquelas contendo o subproduto okara, foi misturada em masseira por nove minutos, moldada em formato oval e deixada em estufa a $40{ }^{\circ} \mathrm{C}$ por $1 \mathrm{~h}$ e 10 min para a fermentação. Após o desenvolvimento, foi assada à temperatura de $180{ }^{\circ} \mathrm{C}$ por $16 \mathrm{~min}$.

TABELA 1 - Formulação padrão para a elaboração dos pães.

\begin{tabular}{lr}
\hline \multicolumn{1}{c}{ Ingrediente } & $\%$ \\
\hline Farinha de trigo & 100 \\
Fermento biológico prensado & 3 \\
Sal & 2 \\
Gordura (creme vegetal com 80\% de lipídios) & 1 \\
Reforçador & 1 \\
Água & $50-60$ \\
\hline
\end{tabular}

\subsection{3 - Análise sensorial}

A análise sensorial do produto foi feita em laboratório, em condições adequadas para tal procedimento, em cabines isoladas, com iluminação adequada e ausência de interferentes tais como odores e ruídos.

a) Teste de preferência: feita por escala hedônica com escala variando de um a nove, de desgostei muitíssimo ao gostei muitíssimo [12]. Foram recrutados aleatoriamente 100 provadores não treinados, com idade entre 16 e 54 anos, sendo 46 do sexo masculino e 54 do sexo feminino. Os provadores receberam nas cabines aproximadamente $10 \mathrm{~g}$ de cada uma das três amostras, um copo de água, caneta e a ficha para a avaliação. Os provadores foram instruídos com relação ao uso da água entre a prova das amostras; e

b) Teste de intenção de compra: a amostra de pão admitida pelos provadores como sendo a mais adequada do ponto de vista sensorial foi utilizada para determinação da intenção de compra. Foi utilizada uma tabela com cinco variáveis que iam do certamente compraria (nota maior $=5$ ), ao certamente não compraria (nota menor $=1$ ), segundo DELLA TORRE [10]. Um total de 100 provadores não treina- 
dos foram recrutados aleatoriamente e submetidos à prova de degustação de uma alíquota de aproximadamente $10 \mathrm{~g}$ da amostra. Além disso, uma amostra íntegra do pão estava na bancada para observação dos aspectos gerais como volume, cor e crosta. Os provadores foram instruídos com relação à utilização da água e da observação das características gerais da amostra.

\subsection{4 - Métodos estatísticos}

Para a organização e validação dos dados experimentais das análises sensoriais, foram utilizados o método de análise de variância (ANOVA) e o programa Microsoft Excel versão 2000 [11]. A diferença mínima significativa entre as amostras foi determinada pelo teste de Tukey [16].

\subsection{5 - Determinação da qualidade microbiológica da farinha de okara e dos pães elaborados com a farinha de okara}

As amostras foram submetidas às análises microbiológicas previstas pela legislação para esta classe de produtos alimentícios. Desta maneira, foram realizadas as análises de Coliformes totais e Salmonella sp .

a) Método para determinação de Coliformes totais - Contagem pelo método do número mais provável (NMP) [18]; e

b) Método para determinação de Salmonella sp - Enriquecimento em caldo seletivo [18].

\subsection{6 - Determinação do volume dos pães}

Foi utilizado o método de deslocamento de sementes (linhaça) determinando, portanto, o volume de sementes de linhaça necessário para cobrir a amostra até um ponto préestabelecido em um béquer padronizado de $500 \mathrm{~mL}$. Assim, quanto maior o peso em gramas, correspondente ao volume das sementes, menor o volume do pão. Após a retirada dos pães do forno, tendo-se atingido a temperatura ambiente, uma alíquota de aproximadamente $20 \%$ das amostras foi submetida ao procedimento de determinação do volume indiretamente, de acordo com esta metodologia. Dos valores obtidos pelas determinações foi realizada a média.

\section{3 - RESULTADOS E DISCUSSÃo}

\section{1 - Composição média dos grãos de soja, do extrato aquoso e do okara}

A composição média dos grãos de soja utilizados na elaboração do extrato aquoso foi determinada e os resultados são mostrados na Tabela 2, estando de acordo com os reportados por JACKSON et al. [19]

De acordo com a Tabela 2, pode ser observado que, em peso seco, 37,0\% referem-se aos componentes protéicos, $13,0 \%$, aos lipídicos, $2,8 \%$, a cinzas, sendo que $47,2 \%$ do
TABELA 2 - Composição média dos grãos de soja, do extrato aquoso e do okara em base seca (g/100 g).

\begin{tabular}{lccccc}
\hline & $\begin{array}{c}\text { Cinzas } \\
\text { (DP) }\end{array}$ & $\begin{array}{c}\text { Proteínas } \\
\text { (DP) }\end{array}$ & $\begin{array}{c}\text { Lipídios } \\
\text { (DP) }\end{array}$ & \multicolumn{2}{c}{ Carboidratos totais } \\
\cline { 5 - 6 } & & & & $\begin{array}{c}\text { Carb. } \\
\text { sol. }\end{array}$ & $\begin{array}{c}\text { Fibras } \\
\text { alim. }\end{array}$ \\
\hline Soja & $4,7-0,064$ & $37,3-0,078$ & $21,2-0,678$ & 28,8 & 8,0 \\
Extrato & $2,4-0,009$ & $33,0-0,026$ & $17,7-0,071$ & $46,9^{*}$ & Traços \\
aquoso & & & & & \\
Okara & $2,8-0,003$ & $37,0-0,019$ & $13,0-0,049$ & $4,7^{*}$ & 42,5 \\
\hline
\end{tabular}

total está diretamente relacionado aos carboidratos do okara e $42,5 \%$, a fibras alimentares. Os resultados são compatíveis com os dados citados por JACKSON et al. [19] O porcentual protéico encontrado foi superior aos valores relatados por VAN DER RIET, CILLIERS \& DATEL [30], de $25,4 \%$ a $28,4 \%$; esta variação pode ter sua origem em fatos relacionados ao processo de extração, já que a concentração protéica do extrato aquoso analisado por meio do presente trabalho é inferior aos valores reportados pela literatura. O conteúdo lipídico do subproduto analisado também se encontra acima daquele retratado pelo mesmo autor, de 9,3\% a $10,9 \%$. Para o porcentual de umidade deste subproduto de soja, os valores relatados por Jackson variam de $76-80 \%$, sendo próximos àqueles encontrados na presente pesquisa, que foram de $75,1 \%$.

Com relação à composição centesimal média do extrato aquoso elaborado a partir da soja analisada, valores que podem ser verificados na Tabela 2 , foram obtidos valores de $94,2 \%$ de umidade e a porcentagem média de seus componentes em base seca foi de $2,4 \%$ de cinzas, $17,7 \%$ de lipídios, $33,0 \%$ de proteínas e $41,4 \%$ de carboidratos. Com relação ao porcentual de umidade, o valor encontrado está acima daquele da literatura, de 90,8\%. Tal fato pode ser explicado: as concentrações dos componentes são inferiores àquelas da literatura, de $39,0 \%$ para as proteínas, $21,7 \%$ para os componentes lipídicos e 5,4\% para os minerais, contra $33 \%, 17,7 \%$ e $2,2 \%$ para os mesmos componentes quando determinados para o extrato analisado. As taxas de extração do equipamento utilizado para a elaboração do extrato em questão ficaram aquém daquelas obtidas para a elaboração do extrato relatado por JACKSON et al. [19]

\section{2 - Teor de isoflavonas do subproduto okara}

Foi encontrada uma concentração de $35,7 \mathrm{mg} \%$ de isoflavonas totais no subproduto okara analisado. A isoflavona genistina atingiu a maior concentração dentre todas as isoflavonas determinadas, 9,3 $\mathrm{mg} \%$, seguida de 6"-OAcetil-genistina com 8,19 mg\%, 6"-0-Malonil-daidzina com 7,2 $\mathrm{mg} \%$ e daidzina com $5,4 \mathrm{mg} \%$. Os valores encontrados para as demais formas de isoflavonas determinadas estão na Tabela 2. JACKSON et al. [19] relataram que aproximadamente $1 / 3$ das isoflavonas presentes na soja permanecem no subproduto da obtenção do extrato aquoso. Pode-se admitir que a soja que deu origem ao subproduto analisado nesta pesquisa apresenta aproximadamente $108 \mathrm{mg} \%$ de 
isoflavonas totais. A concentração de isoflavonas na soja pode variar de maneira bastante expressiva. Variedades de soja com concentrações de isoflavonas variando de $141,0 \mathrm{mg} \%$ a $389 \mathrm{mg} \%$ foram encontradas [19]. No mesmo ano, CARRÃO-PANIZZI et al. [6] encontraram variações do teor de isoflavonas de diferentes cultivares de soja em torno de $140 \mathrm{mg} \%$ a $300 \mathrm{mg} \%$, enquanto PARK et al. [24]. encontraram concentrações que variaram de $114 \mathrm{mg} \%$ a $300 \mathrm{mg} \%$.

Considerando as funções já devidamente comprovadas das isoflavonas, como seu poder antioxidante, prevenindo doenças crônico-degenerativas, como certos tipos de câncer e doenças cardíacas, é interessante considerar a presença de tais componentes em produtos desenvolvidos com o subproduto okara. Desta maneira, o enriquecimento de produtos alimentícios com subprodutos de soja, como o okara, pode ser uma prática importante na prevenção de certas patologias.

TABELA 3 - Teor de isoflavonas do okara.

\begin{tabular}{lcc}
\hline \multicolumn{1}{c}{ Isoflavona } & Média $\mathbf{~ m} \%$ & C.V. $\%$ \\
\hline Daidzina & 5,40 & 5,28 \\
Glicitina & 1,02 & 12,75 \\
Genistina & 9,30 & 4,46 \\
6"-O-Malonil-dadzina & 7,23 & 0,83 \\
6"-O-Malonil-glicitina & 0,65 & 7,69 \\
6"-O-Malonil-denistina & 0,26 & 2,25 \\
6"-O-Acetil-dadzina & 0,34 & 1,71 \\
6"-O-Acetil-glicitina & 0,31 & 0 \\
6"-O-Acetil-genistina & 8,19 & 4,03 \\
Daidzeína & 1,61 & 1,86 \\
Gliciteína & 0,13 & 0 \\
Genisteína & 1,46 & 2,05 \\
Total & 35,73 & 3,85 \\
\hline
\end{tabular}

\section{3 - Qualidade microbiológica da farinha de okara}

As análises microbiológicas da farinha elaborada com o subproduto okara apresentaram resultados satisfatórios, dentro dos padrões exigidos pela Agência Nacional de Vigilância Sanitária. A determinação de coliformes totais apresentou valores inferiores a 10,0 UFC/g, enquanto a verificação de Salmonella sp determinou ausência dos microrganismos nas condições teste.

O padrão microbiológico preconizado para a determinação de coliformes, segundo a RDC 12/2001-MS, é de até 102 UFC/g. Para a determinação de Salmonella sp, o padrão exigido é a ausência do patógeno na amostra.

\section{4 - Avaliação da composição química dos pães}

A composição centesimal dos pães elaborados com 0,5 , 10 e 15\% da farinha de okara está reportada na Tabela 4.

Pode-se observar que ocorreu um aumento muito pequeno da umidade, e aumentos mais expressivos nas con-
TABELA 4 - Composição centesimal dos pães com 0, 5, 10 e 15\% de farinha de okara, em base úmida.

\begin{tabular}{lcccccc}
\hline Okara & Umidade & Cinzas & Proteínas Lipídios & $\begin{array}{c}\text { Carb. } \\
\text { totais }\end{array}$ & $\begin{array}{c}\text { Fibras } \\
\text { alim. }\end{array}$ \\
\hline \multicolumn{7}{c}{$\%$} \\
\hline 0 & 29,1 & 2,3 & 12,7 & 0,5 & 81,9 & 2,6 \\
5 & 29,3 & 2,5 & 19,9 & 0,6 & 72,4 & 4,6 \\
10 & 29,4 & 2,7 & 21,1 & 1,1 & 68,6 & 6,5 \\
15 & 30,8 & 3,0 & 23,1 & 1,5 & 64,0 & 8,4 \\
\hline
\end{tabular}

centrações de lipídios, proteínas e fibra alimentar dos pães adicionados de maiores concentrações do okara.

Com relação ao conteúdo de fibra alimentar das diferentes formulações, pode-se observar um acréscimo significativo de uma formulação à outra com o aumento da concentração do subproduto adicionado. Os pães elaborados sem a adição de okara apresentam uma porcentagem de fibra alimentar na ordem de $2,6 \%$; os pães com adição de $5 \%$ de okara têm um aumento de pouco mais de $73 \%$, para este componente, atingindo um teor de 4,5\%. Para os pães adicionados de $10 \%$ de okara, este aumento foi maior, passando para 6,5\% de fibra alimentar, ou seja, um aumento de aproximadamente $147 \%$. Da mesma maneira, as amostras adicionadas de $15 \%$ do subproduto atingem um conteúdo de aproximadamente $8 \%$ de fibra alimentar, o que representa um acréscimo de $221 \%$. Pode-se considerar que os produtos suplementados com okara em qualquer uma das concentrações estudadas têm certo enriquecimento em fibras. Em se tratando do pão com 5\% de okara, a concentração de $4,5 \%$ de fibra alimentar o inclui na categoria dos produtos denominados "fonte" de fibras, já que este valor supera o mínimo necessário de 3 g/100 g. Para os pães suplementados com 10\% de okara, as amostras passam a ser incluídas na categoria de produtos com "alto teor" de fibras, por apresentarem concentração superior a $6 \mathrm{~g}$ de fibras/100 g de sólidos [4]. As denominações "fonte" e "alto teor" e os valores limites constam da Portaria 27/98 da ANVISA [4].

Com relação ao teor de isoflavonas nos pães, fazendo-se uma análise comparativa com os resultados obtidos pela determinação realizada no subproduto e considerando-se que com o cozimento os pães perdem cerca de $22,4 \%$ de seu peso inicial, o teor de isoflavonas nos pães contendo $10 \%$ de okara é de cerca de 4,6 mg\%. Desta maneira, estudos adicionais poderiam ser realizados a fim de possibilitar o desenvolvimento de um alimento funcional no que diz respeito à presença e ação de tais componentes.

\section{5 - Determinação do volume dos pães elaborados com $0,5,10$ e $15 \%$ de okara}

Para o pão controle, o volume de linhaça necessário para alcançar o limite pré-determinado no béquer correspondeu a $823 \mathrm{~mL}$, e os volumes determinados para os pães elaborados com 5, 10 e 15\%, corresponderam a 835, 860 e $986 \mathrm{~mL}$, respectivamente. Pode-se perceber que, pela adição 
do subproduto okara, existe certo comprometimento do volume, pela diminuição da concentração do glúten do trigo na massa. Além da perda da força e resistência da massa, existe um aumento relativo da umidade das amostras pela elevação do teor de fibras, fato este que pode ser verificado por meio dos dados já demonstrados de composição centesimal dos pães elaborados. A variação de volume do pão controle para o pão com adição de $5 \%$ de okara foi de $1,5 \%$. Variação de volume superior ocorreu comparando-se os pães com $5 \%$ e $10 \%$ de okara (2,9\%), e dos pães com $10 \%$ e $15 \%$ de subproduto (12,8\%). Estes valores demonstraram que a redução mais significativa de volume ocorre a partir da adição de $10 \%$ de subproduto, sendo este um indicativo do montante a ser adicionado para a obtenção de um produto de elevada aceitação no que diz respeito ao volume. Os valores de volume e sua redução, quando comparadas as diferentes formulações analisadas, estão demonstrados na Tabela 5.

TABELA 5 - Volume dos pães elaborados e redução do volume nas diferentes formulações.

\begin{tabular}{lcccc}
\hline & Controle & 5\% okara & 10\% okara & 15\% okara \\
\hline $\begin{array}{l}\text { Volume (expresso em } \\
\mathrm{mL} \text { de linhaça) }\end{array}$ & 823 & 835 & 860 & 986 \\
Perda de volume \% & \multicolumn{2}{c}{1,5} & & \\
& \multicolumn{4}{c}{2,9} \\
\end{tabular}

A perda significativa de volume dos pães elaborados com quantidades do subproduto acima de $10 \%$ sugere, a princípio, a concentração média ideal a ser utilizada para a elaboração e boa aceitação das amostras.

\section{6 - Avaliação microbiológica dos pães}

As análises microbiológicas dos pães contendo 0, 5, 10 e $15 \%$ de okara apresentaram resultados satisfatórios, dentro dos padrões exigidos pela Agência Nacional de Vigilância Sanitária. A determinação de coliformes totais resultou em valores inferiores a 10,0 UFC/g e a análise para detecção de Salmonella sp apresentou um resultado negativo (ausência da bactéria) nas condições teste.

\section{7 - Avaliação sensorial dos pães}

a) Teste de preferência

Os resultados do teste de preferência para as amostras contendo 5,10 e $15 \%$ foram obtidos por meio de notas conferidas pelos provadores, sendo tais valores 8,0, 7,8 e 6,6 , respectivamente.

Por meio da observação dos resultados do teste sensorial de preferência e das médias atingidas para cada uma das amostras, pode-se verificar uma aceitação bastante próxima para os pães elaborados com 5\% e 10\% de okara, 8,0 e 7,8, respectivamente. Já para a amostra contendo $15 \%$ de okara, o valor da média alcançada foi de 6,6, demonstrando uma redução de sua aceitabilidade. Desta maneira, foi realizada a análise de variância (ANOVA) dos resultados, que consta na Tabela 6 e, por meio de tal determinação, pode-se afirmar que existe diferença significativa entre as amostras, ao nível de $1 \%$, já que o valor $\mathrm{F}$ encontrado foi 19,76 , sendo este superior ao valor tabelado $(4,60)$.

TABELA 6 - Quadro de Análise de Variância.

\begin{tabular}{ccccc}
\hline Causas da variação & G.L & S.Q & Q.M & F \\
\hline Amostras & 2 & 115,547 & 57,77 & 19,76 \\
Provadores & 99 & 50,333 & 0,51 & - \\
Resíduo & 198 & 578,67 & 2,923 & - \\
Total & 299 & 744,55 & 2,49 & - \\
\hline
\end{tabular}

Em seguida, foi realizado também o teste de Tukey, para determinar se havia diferença significativa entre as médias. O valor DMS (diferença mínima significativa) foi calculado e, para que as amostras sejam consideradas diferentes, esta diferença deverá ser de no mínimo 0,57. Os valores das médias das amostras obtidas pelo teste de aceitação determinam a diferença numérica entre elas, e estes estão reportados na Tabela 7 .

TABELA 7 - Determinação da diferença entre as amostras.

\begin{tabular}{lcc}
\hline \multicolumn{1}{c}{ Amostra } & Média obtida & \\
\hline Amostra 1 (A1) 5\% de okara & 8,02 & $\mathrm{~A} 1-\mathrm{A} 2=0,24<0,57$ \\
Amostra 2 (A2) 10\% de okara & 7,78 & $\mathrm{~A} 2-\mathrm{A} 3=1,17>0,57$ \\
Amostra 3 (A3) 15\% de okara & 6,61 & $\mathrm{~A} 1-\mathrm{A} 3=1,41>0,57$ \\
\hline Obs: DMS $=0,57$.
\end{tabular}

Por meio dos dados da Tabela 6 , pode-se verificar ausência de diferença significativa para as amostras A1 e A2, ou seja, aquelas com $5 \%$ e $10 \%$ de okara, respectivamente, já que o valor numérico para tal diferença é de 0,24 , inferior ao DMS de 0,57. Para as amostras A2 e A3, com 10\% e 15\% de okara, existe diferença significativa da ordem de 1,17, superior ao valor de DMS, porém maior diferença ainda ocorre quando comparadas as amostras A1 e A3, com 5\% e $15 \%$ de okara, respectivamente, em que o valor numérico desta diferença é de 1,41.

b) Intenção de compra dos pães contendo 10\% de okara.

A partir da análise estatística verifica-se que as amostras contendo $5 \%$ e $10 \%$ de okara não diferem significativamente, além disso, observando as medidas de volume das amostras, pode-se admitir que a utilização de uma substituição na ordem de $10 \%$ de resíduo vem ao encontro dos objetivos do presente trabalho. Desta maneira, foi realizado um teste para verificação da intenção de compra desta amostra. A verificação da intenção de compra do produto panificado contendo $10 \%$ de resíduo okara teve como resultado um parecer médio entre cinco e quatro, ou seja, certamente compraria e provavelmente compraria. Do ponto de vista da intenção de compra dos provadores, a amostra testada obteve valor médio de 4,2 . 


\section{4 - CONCLUSÓES}

- A caracterização físico-química do okara demonstrou valores para os componentes químicos como proteínas e principalmente fibras, que confirmam os dados bibliográficos e apresentam-se favoráveis do ponto de vista nutricional. Assim, a denominação de subproduto pode ser adotada como mais apropriada do que a de resíduo. Com relação ao teor protéico do subproduto okara analisado pelo presente estudo, os resultados encontrados revelam índices superiores aos reportados pelo INSTITUTO DE TECNOLOGIA DE ALIMENTOS [18]. Em contra partida, o valor da concentração protéica do extrato aquoso analisado apresentou-se menor do que aquele relatado pelo mesmo autor; desta maneira os dados sugerem uma menor eficiência de extração do equipamento utilizado neste estudo;

- O teor de isoflavonas do subproduto encontra-se dentro do esperado, levando-se em consideração que este foi obtido de uma variedade de soja utilizada comercialmente para a extração de óleo e que apresenta concentração dentro dos limites mínimos citados pela literatura;

- As análises microbiológicas da farinha de okara apresentaram resultados satisfatórios, o que aponta para a utilização deste subproduto com segurança enquanto ingrediente ou suplemento alimentício;

- Os pães elaborados com 0, 5, 10 e 15\% de farinha de okara apresentaram diferentes volumes, porém, a maior diferença foi encontrada quando se utilizou $15 \%$ do subproduto para a elaboração dos pães;

- Com a análise sensorial de preferência das três diferentes amostras de pães (com 5, 10 e 15\% de okara) e a realização da análise de variância dos dados, constatouse que há diferença estatística entre elas. Por meio do teste de Tukey, concluiu-se que as amostras com $5 \%$ e $10 \%$ de subproduto não são estatisticamente diferentes, porém a amostra contendo $15 \%$ do subproduto é estatisticamente diferente das outras duas;

- A caracterização físico-química dos pães adicionados de okara revelou aumento expressivo do teor protéico e do teor de fibras, quando da adição do subproduto, sendo que as amostras contendo $5 \%$ de subproduto passaram à categoria de produtos alimentícios considerados "fonte" de fibras, e as amostras contendo $10 \%$ e $15 \%$ de subproduto puderam ser classificadas como produtos alimentícios com "alto teor" de fibras; e

- Considerando-se os aspectos de volume dos pães, adicionados do subproduto okara, os resultados das análises sensoriais de aceitação e intenção de compra realizadas e, principalmente, as características físico-químicas, conclui-se que $10 \%$ de farinha do subproduto okara é a concentração mais adequada para ser adicionada em substituição à farinha de trigo, em pães elaborados pela formulação padrão adotada neste trabalho.

\section{5 - REFERÊNCIAS BIBLIOGRÁFICAS}

[1] AOAC. Official Methods of Analysis of the Association of Analytical Chemists. 40 ed. Washington: [s.n.], 1990.

[2] A SOJA. Disponível em: <http://www.cnpso.embrapa. br/index.php?op_page $=22 \&$ cód_pai $=16>$ Acesso em: 12 nov. 2004.

[3] BAARDSETH, P.; KVAAL, K.; LEA, P.; ELLEKJAER, M. R.; FAERGESTAD, E. M. The Effects os Bread Making Process and Wheat Quality on French Baguettes. Journal of Cereal Science, v. 32, p. 73-87, 2000.

[4] BRASIL. Ministério da Saúde. Secretaria de Vigilância Sanitária. Portaria n0 27/98 SVS/MS -- Regulamento Técnico Referente à Informação Nutricional Complementar. Disponível em: <http://e-legis.bvs.br/leiref/public/showAct.php?id=97\#. Acesso em: 2 jan. 2005.

[5] BUSLIG, B. S.; MANTEHY, J. A. Flavonoids in the living cell. New York: Kluwer Academic, 2002. p. 61-76.

[6] CARRÃO-PANIZZI, M. C.; BELÉIA, A. P.; KITAMURA, K.; OLIVEIRA, M. C. N. Effects of genetics and environment on isoflavone content of soybean from different regions of Brazil. Pesquisa Agropecuária Brasileira, v. 34, n. 10, p. 1787-1795, 1999.

[7] CHAN, W. M.; MA, C. Y. Acid modification of proteins from soymilk residue (okara). Food Research International, London: Elsevier, v. 32, p.119-127, 1999.

[8] CHIARELlO, M. Soja e os Alimentos Funcionais. In: ENCONTRO FRANCO BRASILEIRO DE BIOCIÊNCIA E BIOTECNOLOGIA - ALIMENTOS FUNCIONAIS E NUTRACÊUTICOS, 2002, Brasília. Resumos das Palestras...Brasília: Embrapa, 2002. p. 3-15.

[9] CONSEJO NACIONAL DE COORDINACIÓN DE POLÍTICAS SOCIALES. Consideraciones sobre la soja en la alimentación. Buenos Aires, 2002. 17p.

[10] DELla TORRE, J. C. de M., RODAS, M. A. de B., BADOLATO, G. G. et al. Perfil sensorial e aceitação de suco de laranja pasteurizado minimamente processado. Ciência e Tecnologia Alimentos, v. 23, n. 2, p. 105-111, maio/ago. 2003.

[11] DHINGRA, S.; JOOD, S. Organoleptic and nutritional evaluation of wheat breads supplemented with soybean and barley flour. Food Chemistry, London, v. 77, p. 479-488, 2001.

[12] DUTCOSKY, S. D. Análise Sensorial de Alimentos. 20 ed. Curitiba: Editora Universitária Champagnat, 1996. 123 p.

[13] DUTRA de OLIVEIRA, J. E.; MARCHINI, J. S. Ciências Nutricionais. São Paulo: Sarvier, 1998. 403 p.

[14] FAOSTAT Database. Agricultural production. Crops Primary. Disponível em: < http://http://faostat.fao.org/ faostat/form/collection=Production. Crops. Primary\% Domain $=$ Production $\%$ servlet $=1 \&$ hasbulk $=\&$ version $=$ ext\&language $=\mathrm{EN}>$. Acesso em: $18 \mathrm{dez} .2004$.

[15] GENTA, H. D.; GENTA, M. L.; ÁLVAREZ, N. V.; SANTANA, M. S. Production and acceptance of a soy candy. Journal of Food Engineering, v. 53, p. 199-202, 2002.

[16] GÓES-FAVONI, S. P .; BELÉIA, A. Del. P.; CARRÃO-PANIZZI, M. C.; [21]., J. M. G. Isoflavonas em produtos comerciais de soja. Ciência e Tecnologia de Alimentos, v.24, n.4, p. 582-586, out./dez. 2004. 
[17] INSTITUTO ADOLFO LUTZ. Normas analíticas do Instituto Adolfo Lutz. 3 ed. São Paulo: Imesp, 1985, v. $1,533 \mathrm{p}$.

[18] INSTITUTO DE TECNOLOGIA DE ALIMENTOS. Métodos de Análise Microbiológica de Alimentos - Manual Técnico, 14. Campinas: ITAL, 1995, 230p.

[19] JACKSON, C. J. C.; DINI, J. P.; LAVANDIER,C.; RUPASINGHE, H. P. V.; FAULKNER, H.; POYSA, V.; BUZZELL, D.; De GRANDIS, S. Effects of processing on the content and composition of isoflavones during manufacturing of soy beverage and tofu. Process Biochemistry, London, v. 37, p. 1117-1123, 2001.

[20] LIU, K. Soybeans. Gaithersburg: Aspen Publishers, 1999. $532 \mathrm{p}$.

[21] MA, C. Y.; W. S.; KWOK, K. C.; KWOK, F. Isolation and characterization of proteins from soymilk residue (okara). Food Research International, London, v. 29, n. 8, p. 799-805, 1997 .

[22] MANDARINO, J. M. G. A Soja e a Saúde Humana . In: ENCONTRO FRANCO BRASILEIRO DE BIOCIÊNCIA E BIOTECNOLOGIA - ALIMENTOS FUNCIONAIS E NUTRACÊUTICOS, 2002, Brasília. Resumos das Palestras...Brasília: Embrapa, 2002. p. 9-11.

[23] O'TOOLE, D. K. Characteristics and Use of Okara, the Soybean Residue from Soy Milk Production-A Review. Journal of Agriculture and Food Chemistry, v. 47, p. 363-371, 1999.

[24] PARK, Y. K.; AGUIAR, C. L.; ALENCAR, S. M.; MASCARENHAS, H. A. A.; SCAMPARINI, A. R. P. Avaliação do teor de isoflavonas em soja Brasileira. Ciência e Tecnologia de Alimentos, v. 3, n. 3, p. 156-160, 2001.

[25] PROYECTO PILOTO de empreendimento solidário de producción, elaboración y distribuición de alimentos de soja para assistência alimentaria em comedores cominitarios del partido, 2002.
[26] QUAGLIA, G. Ciencia y tecnología de la panificación. Zaragoza: Acribia, 1991. 485 p.

[27] SOMMIER, A.; CHIRON, H.; COLONNA, P.; VALlE, G. D.; ROUILLÉ, J. An instrumented pilot scale oven for the study of French bread baking. Journal of food Engineering, v. 69, p. 97-106, 2005.

[28] SOUZA, G.; VALLE, J. L. E.; MORENO, I. Efeitos dos componentes da soja e seus derivados na alimentação humana. Boletim da Sociedade Brasileira de Ciência e Tecnologia de Alimentos, Campinas, v. 34, n. 2, p. 61-69, jul./dez. 2000.

[29] STAUFER, C. E. Soy protein in baking. Technical Foods Consultants, ASA: (American Soybean Association): Cincinnati: 2002, 30 p.

[30] VAN DER RIET, W. B.; CILLIERS, J. J.; DATEL, J. M. Food chemical investigation of tofu and its byproduct okara. Food Chemistry, v. 34, p. 193-202, 1989.

[31] WALISZEWSKI, K. N.; PARDIO, V.; CARREON, E. Physicochemical and Sensory Properties of Corn Tortillas Made from Nixtamalized Corn Flour Fortified with Spent Soymilk Residue (okara). Journal of Food Science, v. 67, n. 8, p. 3194-3197, out. 2002.

[32] WANG, H. L.; CAVINS, J. F. Yield and amino acid composition of fractions obtained during tofu production. Cereal Chem., v. 66, p. 359-361, 1989.

[33]WANG, J.; ROSELL, C. M.; de BARBER, C. B. Effect of the addition of different fibres on wheat dough performance and bread quality. Food Chemistry, v. 79, p. 221-226, 2002.

\section{6 - AGRADECIMENTOS}

Secretaria Municipal de Abastecimento da Prefeitura de Curitiba - PR e EMBRAPA - SOJA de Londrina - PR 